\title{
AS CIÊNCIAS DA EMOÇÃo ESTÃo IMPREGNADAS DE POLÍTICA? CATHERINE LUTZ E A QUESTÃo DO GÊNERO DAS EMOÇÕES ${ }^{\star}$
}

Vinciane Despret ${ }^{\star}$

\begin{abstract}
Resumo
O texto apresenta uma reflexão pautada na articulação entre emoção e ciência. Sendo esta possível ao deslocar o entendimento sobre o fenômeno das emoções distante do familiar, onde este é pensado como fenômeno pouco racional. Ao centrar atenção no trabalho da etnopsicóloga Catherine Lutz sobre as emoções dos habitantes da ilha Ifaluk, o texto apresenta outra perspectiva sobre as emoções e sobre o processo de pesquisa: articulando emoção à política, propondo a construção do problema junto com o conhecimento do campo de pesquisa e dando ao pesquisador a possibilidade de transformação no processo da investigação.
\end{abstract}

Palavras-chaves: emoção; pesquisa; politica.

\section{Are emotion sciences full of Politics? CATHERINE LuTZ AND THE QUESTION OF THE GENDER OF EMOTIONS}

\begin{abstract}
The text presents a reflection based on the articulation between emotion and science. This is possible when moving your understanding of the phenomenon of emotions away from familiar, where this is thought of as a little rational phenomenon. By focusing on the work of ethnopsychology Catherine Lutz on emotions of Ifaluk island's inhabitants, the text presents another perspective on emotions and on the search process: articulating emotion to politics, proposing the construction of the problem along with the knowledge of the search field and giving the researcher the possibility of transformation in the process of research.
\end{abstract}

Keywords: emotion; search; politics.

\footnotetext{
^ Tradução de Carlos Marconi. Revisado por Marianne Strumpf.

$\star \star$ Doutora em Filosofia e Letras. Departamento de Filosofia. Universidade de Liège Place du XX Aout 74000 Liège, Bélgica.

E-mail: V.Despret@ulg.ac.be
} 
Partamos deste princípio bem conhecido pelos antropólogos: o peixe não vê a água do aquário. Dizer que peixe não vê a água do aquário designa, de fato, a situação na qual estamos quando tentamos pensar as coisas: as experiências, as maneiras de viver e de se organizar nos são tão familiares que nos é difícil pensálas de outra forma. Dessa forma, quando pensamos o que é uma pessoa, uma quantidade de características vem em socorro à definição: pensaremos na consciência, na autonomia da vontade, na capacidade de ser responsável por seus atos. Ora, se interrogamos outras culturas sobre esse assunto, nós nos espantamos: ser uma pessoa pode ter uma quantidade de outras significações: a consciência não é requerida (o caso do Japão é exemplar a esse respeito), a autonomia da vontade tampouco é requisitada (por exemplo, nas culturas que não têm a noção de responsabilidade vinculada à da individualidade) etc.

O problema das emoções é bem semelhante. Nós as consideramos como fenômenos pouco racionais, mais arcaicos, biologicamente fundados etc. $\mathrm{O}$ encontro com outras culturas nos reserva muitas surpresas.

É com alguns desses encontros que eu gostaria de abordar essa questão.

Gostaria, inicialmente, de esclarecer os riscos desta exploração: não se trata somente de multiplicar os repertórios daquilo que podem ser as emoções, trata-se, primeiro e antes de tudo, de aprender a considerar as nossas, de forma diferente, de tornar visíveis coisas que para nós são tão naturais que se tornaram invisíveis. Trata-se de aprender a pensar nos contrastes, o que quer dizer aprender a "nos" pensar nos contrastes.

Eu vou acompanhar mais particularmente uma antropóloga específica, ainda que eu me interesse por outros de seus colegas quando eles conseguem especificar alguns aspectos daquilo que nós questionamos ao longo de nosso percurso. Se escolhi essa pesquisadora é porque ela, melhor que todos os outros, mostrou que a verdadeira aposta de suas pesquisas era antes de tudo o conhecimento de nós mesmos. Depois, porque, no quadro que nos reúne, ela, de maneira magistral, ligou a questão das emoções à da política, isto é, àquela das relações de poder. Chegaremos a isso rapidamente. Comecemos, inicialmente, por apresentá-la.

Catherine Lutz, porque é dela que se trata, é uma etnopsicóloga americana; ela cresceu em uma família de classe média de um subúrbio de New Jersey; ao fim dos anos 1970, partiu para efetuar sua primeira pesquisa de campo em um minúsculo atol do Pacífico ocidental, a ilha de Ifaluk. Durante todo o tempo de sua pesquisa, ela vai viver com os cerca de 400 habitantes desta ilha; ela vai interrogá-los sobre suas emoções e as teorias por intermédio das quais eles as explicam, as compreendem e as interpretam: em outros termos, ela vai fazer o inventário das etnoteorias que formam a etnopsicologia dos Ifaluk; isto vai conduzi-la a interrogar as nossas.

$\mathrm{O}$ fato de eu privilegiar, desde as primeiras linhas, o contexto no qual a pesquisadora cresceu para abordar os problemas da passagem de uma cultura para outra não atende a qualquer exigência narrativa ou biográfica. Eu o faço porque esta especificação aparece ao longo de seus próprios escritos, e da qual ela não é inocente. 
Podemos a princípio traduzir essa especificação como uma precaução metodológica que se tornou bastante usual no domínio da antropologia. Essa precaução corresponde àquela que se chama "exigência reflexiva". Em antropologia, essa maneira de proceder se tornou inerente à própria pesquisa: lembrar de onde se vem, de onde se fala, faz parte atualmente do caderno de encargos do trabalho do antropólogo: toda pesquisa é uma pesquisa "situada".

Lutz (1988), além disso, vai mais amplamente se submeter a essa exigência, explicitando, no livro que relata seu encontro com os Ifaluk, as origens e o contexto no qual ela começou seu próprio trabalho e as questões que o guiaram. Eu proponho a vocês segui-la, pois se trata inteiramente de um empenho crítico e reflexivo que nos permitirá compreender os problemas que podem se apresentar quando nos engajamos nas relações com outras culturas, e o que podemos esperar em termos de expectativas. Para fazer isso, iremos explorar o domínio das condutas humanas muito particular ao qual esta antropóloga se vinculou: o das emoções.

Lutz nos convida de início a compreender o fato de que ela tenha escolhido as emoções como objeto de pesquisa à luz da influência da tomada de consciência feminista dos anos setenta. Nesse contexto, explica ela, algumas pesquisadoras se interessaram pelas características geralmente atribuídas às mulheres - a psicologia era majoritariamente, até aquela época, uma psicologia de homens ou uma psicologia em que os homens constituíam o modelo. Uma constante se impõe muito rapidamente a Lutz. Os estudos das universitárias americanas apresentam nessa época uma constante, refletindo um traço cultural particular: elas associam de maneira recorrente mulheres, emoções e tudo aquilo que é considerado como tendo pouco valor. As emoções são, nesta literatura, consideradas como os processos mais arcaicos, até mesmo primitivos, incontroláveis, menos sofisticados, dependendo frequentemente da patologia.

O fato de se associar as emoções às mulheres não dependeria, portanto, da ideologia do gênero que impregna a cultura americana? Em outros termos, as concepções predominantes das emoções no discurso universitário não traduziriam, antes de tudo, as relações de poder, particularmente legíveis nessa associação de características desvalorizadas ao gênero minoritário? Observemos inicialmente que o contraste "razão-emoção" que funda a definição das emoções se articula ao que instituímos entre "espaço público" (espaço da razão) e "espaço doméstico ou privado" como espaço da sensibilidade. Atribuir a emoção a uma categoria coletiva pode então significar sua exclusão do espaço político.

Numerosas pesquisas vieram inclusive confirmar e apoiar esta crítica: o contraste emoção/razão, que, aliás, confirma outros dualismos afiliados - passividade/atividade; natureza/cultura; corpo/consciência/ subjetividade/pensamento racional; valores/fatos; transbordamento/controle-vontade - é um contraste que hierarquiza os seres. Do lado dos detentores privilegiados da razão, encontraremos aqueles que têm o direito do exercício no espaço público (os homens, se possível, brancos e civilizados); do lado das emoções, encontraremos aqueles que dele são excluídos: as mulheres, as crianças, aqueles que durante muito tempo 
chamamos primitivos, até mesmo as classes trabalhadoras (sempre à beira de um motim). Lutz (1988, p. 54) escreve, aliás, em conclusão de suas primeiras pesquisas na literatura científica das emoções que:

O conceito de emoção existe em um sistema de relações de poder e desempenha um papel na manutenção deste [....] Identificando, primeiro, as emoções com a irracionalidade, a subjetividade, o caótico e outras características negativas, e em seguida etiquetando as mulheres como o gênero emocional, as crenças culturais reforçam a subordinação ideológica das mulheres.

Ainda segundo Lutz, "Falar de emoções, é ao mesmo tempo falar da sociedade, é falar de poder e política, de relação de afiliação e de aliança, é falar de normalidade e desvio" (LUTZ, 1988, p. 6).

Isso vai levar nossa antropóloga a querer dar uma nova orientação a suas pesquisas: ela quis encontrar um campo de pesquisa que the permitisse colocar esta associação "mulheres-emoções-características desvalorizadas" à prova: encontrar-se-ia uma associação similar em uma sociedade mais igualitária?

Os motivos políticos (e científicos) não são, entretanto, os únicos em discussão: a história pessoal da antropóloga converge aqui. "Meu pai, [ela conta], era um homem muito emocional. Estávamos sentados à mesa, ele podia chorar de alegria. Eu me dei conta de que o fato de que ele fosse tão impressionável era mal julgado. Aos olhos das pessoas, ele era uma espécie de "macho problemático""

Encontrar uma sociedade na qual estivesse de acordo com a norma, para um homem, falar abertamente de suas emoções ou de manifestá-las fazia então com que se articulassem um projeto científico, um projeto político e um projeto pessoal - aquele de uma filha sofrendo a desqualificação de que seu pai tinha sido o objeto.

Diante da ausência de informações, na literatura dessa época, a respeito da repartição de papéis, ela escolheu três critérios como indicadores prognosticando um determinado igualitarismo: o fato de que o casamento seja matrilocal, que os princípios de herança e filiação sejam matrilineares e que a produção das provisões alimentares esteja sob a responsabilidade das mulheres. Os ifaluk preenchiam as três condições: a residência do casal está fixada na família da esposa, a filiação era matrilinear e as mulheres são as únicas proprietárias das terras da ilha, as quais são cultivadas por elas. Além disso, os antropólogos que os haviam estudado no fim dos anos 1940 e início dos anos 1950 relataram uma quantidade de canções poéticas nas quais os termos exprimindo emoções são recorrentes, o que leva a pensar que a utilização de termos emocionais deve ser relativamente frequente na vida cotidiana. ${ }^{2}$ A leitura desses poemas acabou por convencer Lutz: eles insistem no valor que os ifaluk associam às relações interpessoais, na força das ligações que os unem e na atmosfera pacífica e amistosa que reina na ilha onde a violência parece estar ausente. O que confirma os escritos dos antropólogos. 
O fato de essas últimas características parecerem importantes aos olhos de Lutz nos indica uma outra modalidade de motivações para a pesquisa: esta não era tanto a de uma resposta a questões, quanto uma solução de problemas.

Eu estava consciente, [ela escreve], de que o que eu procurava era muito mais que um local de pesquisa apropriado para estudar o problema da relação entre emoção e cultura. Procurava igualmente pessoas que teriam inventado uma solução cultural que seria não somente diferente da nossa, mas de certa maneira, melhor. Quis ver como era possível para as pessoas organizarem suas vidas de maneira a evitar os problemas que me pareciam debilitar a cultura americana, em particular sua desigualdade de gênero, de classes e sua violência (LUTZ, 1988, p. 17).

O encontro, todavia, não se produzirá sob o signo das soluções: os ifaluk oferecem muitas surpresas em relação àquilo que Lutz esperava encontrar. Não somente o que ela observa se mostra muito frequentemente contraditório com aquilo para o qual estava preparada, mas as contradições parecem inerentes à própria vida social dos Ifaluk. A imagem de uma sociedade pacífica isenta de toda cólera é constantemente colocada em xeque pelas declarações de cólera recorrentes na vida cotidiana. A violência está, todavia, totalmente ausente da ilha. Contradição ainda quando se considera o status das mulheres; as relações igualitárias esperadas são sem cessar contrariadas por discursos descrevendo as mulheres como seres "carentes" e subordinados. Mas, se ela coloca a pergunta, os homens lhe respondem que são as mulheres que têm o poder sobre a ilha. E o papel de chefe de uma das cidades é desempenhado por uma dentre elas. ${ }^{3}$

Ora, e é este o ponto central de sua obra, aquilo que Lutz vai aprender vai modificar radicalmente as próprias motivações de seu projeto: ela procurava soluções entre os "outros"; ela vai aprender a reconstruir o problema de outra forma. É para "nós" que ela será reenviada, é a se interessar por sua própria cultura que ela vai se lançar. É nesse ponto da démarche que a recordação "de onde eu venho", cuja importância em seu trabalho eu assinalei, toma um outro sentido. Não é mais este empenho reflexivo, condição a montante que obriga a pesquisadora a se situar, ele constitui, no presente, a jusante, o próprio objeto de sua pesquisa. Em outros termos, o "de onde eu venho", que no regime da reflexividade se define como uma medida de precaução - e uma cura para o etnocentrismo ${ }^{4}$ - transformase naquilo que se deve construir, aprender e colocar à prova.

Toda etnografia é comparativa e implica levar em conta os dois sistemas de significação, o nosso e aquele de quem interrogamos. O xibolete do método antropológico, entretanto, raramente conduz ao exame simultâneo dos dois sistemas de significação (LUTZ, 1988, p. 44). 
O que significa, do ponto de vista da prática, continua ela, "que a visão do mundo emocional da antropóloga merece tanta atenção quanto aquela da cultura que vamos observar" (LUTZ, 1988, p. 12).

Assim, explica Lutz, na ilha de Ifaluk, o termo ker, que podemos traduzir aproximadamente por "felicidade", é considerado amoral, até mesmo, imoral.

Quando eu tomei consciência que os Ifaluk a sentiam dessa maneira, minha surpresa me assinalou mais que o simples fato de que eu aprendia algo a respeito do modo como eles fazem a experiência da felicidade. Esta surpresa significava também que minha própria etnoteoria implícita da pessoa e das emoções era contraditória em alguns de seus aspectos especialmente o fato que pensamos que a busca da felicidade é um objetivo muito louvável (LUTZ, 1988, p 22).

O saber dos outros transforma nossas maneiras de nos saber. Isto que tinha valor de evidência, ou mesmo de norma, aparecia subitamente, na lição dos contrastes, não somente como contingente - é isso o que temos direito de esperar das colocações em perspectivas, aquilo que, aliás, nos reata ainda à reflexividade - mas, sobretudo, como problemático. O subtítulo do livro do qual é tirado este extrato dá conta do empenho: Everyday sentiments on a Micronesian atoll and their challenge to western theory - "Os sentimentos cotidianos em um atol da Micronésia e seu desafio à teoria ocidental".

Esta pesquisa voltada em direção aos outros se acompanha, por conseguinte, como uma necessidade, simultaneamente a montante e a jusante, de um processo que obriga a pesquisadora a sempre reencaminhar para ela mesma a questão que ela coloca para os outros (“o que é a felicidade para eles?" convoca “o que é felicidade para nós?”).

Será que isso significa ainda que o motivo político que guiou sua pesquisa é totalmente abandonado, e que é necessário considerar que o problema da ligação entre emoção e poder é um problema que somente tem sentido em nossa tradição? Não é o caso. A emoção entre os ifaluk pode ser igualmente considerada como um problema que acompanha a política, que caracteriza as relações de poder. A emoção pode assim ser definida como uma estratégia que se deve aprender, e que emerge tanto mais quando é favorecida pela cultura. Os ifaluk consideram, por exemplo, que a emoção song, que podemos traduzir como uma "cólera justificável" e a emoção metagu, o medo, que responde a ela, são socialmente aprendidos. Não são somente estratégias de negociação visto que essas emoções são utilizadas para negociar as relações com os outros e com a autoridade, mas elas foram também objetos de uma negociação: o medo metagu se ensina às crianças e diversas estratégias são implementadas para favorecer sua emergência, na medida em que ela constitui a reação adequada à cólera justificável e que permite antecipá-la. De outro lado, para se declarar em "cólera justificável”, é necessário poder legitimar esta cólera e negociar esta legitimação com os outros. ${ }^{5} \mathrm{O}$ medo e a cólera justificável são ambos emoções complementares: à cólera song deve 
corresponder o medo metagu. Porque são ambas estratégias sociais, maneiras de entrar em relação e transformar estas relações, maneiras também de se experimentar, estas emoções participam, para aqueles que podem senti-las e exprimilas, da possibilidade de se integrar ao social. As etnoteorias dos ifaluk, explica Lutz, não estabilizam a distinção nítida entre as cognições e os afetos: são ambas atividades que permitem a entrada em relação, e que se explicitam no universo interpessoal. Quando um ifaluk fala de suas emoções, ele não fala do que se passa no interior de sua cabeça, mas daquilo que se passa no mundo e nas suas relações com os outros. ${ }^{6}$ Como tais, elas articulam o universo interpessoal e o universo moral. A metagu é definida, como o são todas as emoções em Ifaluk, em termos de situações que a produzem de maneira típica: por exemplo, visitar pessoas não familiares, encontrar-se em uma festa com desconhecidos, ou ainda encontrar um fantasma malévolo. Ela pode designar também o fato de encontrar um tubarão na água ou de se aventurar numa canoa longe das margens. Mas uma das significações mais importantes é aquela que articula esta emoção a outra, a song, a cólera justificável. O termo "song" é o termo emocional que é exclusivamente utilizado para descrever a reação à transgressão de uma norma cultural, ou de um tabu, por um terceiro. É a emoção de ultraje social e ela é considerada como a emoção apropriada para aqueles que têm uma posição superior: o chefe, os mais idosos e os pais frente a seus filhos. A pessoa que é o objeto da cólera song tem a experiência da emoção metagu. Se uma pessoa sente e exprime a cólera justificável, a outra deve sentir e exprimir a emoção de metagu.

Para estar e se dizer "em cólera justificável" entre os ifaluk, é preciso afirmar que as possibilidades de paz e de bem-estar na ilha foram ameaçadas e é preciso identificar o que ameaça esta ordem moral. E cada vez que o termo é utilizado, observa-se, a cena se enche de atores: há uma regra violada, há alguém que condena e que apela aos outros pela condenação; há o culpado que tem medo desta cólera (ele sente a metagu) e que deverá se emendar à sua maneira. A emoção de cólera que se define não é, portanto, qualquer coisa "que acontece", nem um simples julgamento emocional dos eventos. Aquele que se declara em estado de cólera deverá negociar esta declaração com os outros: o fato de reivindicar a cólera para um ifaluk implica uma caracterização do mundo que deve ser objeto de uma transação. A cólera se negocia, se justifica, mas pode, além disso, se dar como um modo de transformação do mundo. A cólera song somente emerge e é aceita quando as pessoas podem justificar e negociar os valores culturais e as prerrogativas de poder que alguns membros da sociedade possuem naquele momento. Aquele que se declara em cólera deve reunir os outros. E esta negociação deve ter lugar de modo ainda mais singular, por ocasião de mudanças sociais, pois elas se tornam um meio de reformular sua regulação. A cólera justificável, portanto, não é somente o meio de manter a ordem social, ela é um modo de regulação de relações e pode se constituir como uma reivindicação ao poder. E como está ligada ao poder, e ao poder de condenar, constitui ao mesmo tempo um modo de resistência e de condenação social e aquilo que pode favorecer às mudanças (LUTZ, 1990). 
Como acabamos de ver, a emoção entre os ifaluk se inscreve no social e no político. Resta, então, a questão que conduziu a pesquisa à sua origem: como esta concepção pode nos ajudar a ler diferentemente as emoções, a considerá-las de maneira "descentradas" no papel que elas podem desempenhar nos modos de organização. Tentei mostrar a vocês a que ponto nossa concepção de emoções está ela mesma inscrita nos jogos de poder, pelo fato de sua constante desvalorização. Ora, se nos atemos a esta análise, falta-nos alguma coisa: o fato de que, se esta concepção é exatamente aquela que prevalece em numerosos discursos, ela, todavia, não está sozinha. Ao contrário.

Porque, na análise, não podemos esquecer que nossas concepções das emoções são frequentemente habitadas por contradições espantosas. Assim, podemos dizer de nossas emoções que elas são "a vida" e valorizá-las, pois elas são o núcleo mais autêntico da pessoa, mas, ao mesmo tempo, somos capazes de considerá-las como aquilo que faz "com que não sejamos mais nós mesmos" devendo, portanto, serem controladas. As contradições são múltiplas.

Essas contradições que marcam nossas concepções de emoções são, segundo Lutz, simultaneamente, "aquilo que cria e aquilo que é criado por um potencial de ambivalência” (LUTZ, 1988, p. 58). Porque elas coexistem na cultura e no reservatório das etnoteorias, uma e outra versão podem ser ativadas pelos projetos particulares, a cada vez diferentes. Nos discursos de propaganda eleitoral nos Estados Unidos, por exemplo, sobejam exemplos de utilização desta possibilidade de recrutar uma concepção ou outra. Jesse Jackson, durante um discurso pronunciado na Convenção Democrata, em 1984, tenta se desculpar por uma observação insultante a respeito dos eleitores judeus declarando: "Peço aos senhores para considerar que essa falha vem de minha cabeça, não de meu coração" (LUTZ, 1988, p. 68). Todos nós conhecemos a versão alternativa, pois nós já a utilizamos repetidamente: "Desculpe-me, eu não pensei no que eu dizia, eu estava encolerizado - minhas palavras ultrapassaram meus pensamentos". Ouvi recentemente uma ilustração completamente característica desta possibilidade: entrevistaram, na rádio, cidadãos holandeses a respeito da rejeição em massa da constituição européia. Uma das pessoas interrogadas respondeu à questão de como compreender esta rejeição em massa: "votamos com nosso coração". O que mostra bem esta espantosa separação, a mesma no espaço público - e o fato de sublinhar a origem desse voto mostrando bem que as pessoas tinham consciência de haver tomado uma decisão, de uma certa maneira, um pouco "fora do comum", e que se tratava de uma questão ligada mais a valores que à racionalidade - o que nos mostra também que recortamos a percepção da própria realidade de acordo com esse mesmo esquema dualista.

Podemos igualmente, para designar essas contradições, remeter a esta espantosa dualidade teórica relativa às origens das emoções: elas estão no mundo que nos afeta ou em nossa capacidade de transformar o mundo? Este homem é amável porque eu o amo ou eu o amo porque ele é amável? Esse mundo é assustador porque tenho medo ou ele é mesmo o responsável pelo meu espanto? Se os teóricos parecerem ter em sua maioria escolhido a respeito desse tema um lado do campo e defender como a única versão possível uma ou outra concepção, pare- 
cerá que nossas atitudes cotidianas são muito mais hesitantes ${ }^{7}$ ou flexíveis. Posso sair de casa em uma manhã chuvosa como é típico na Bélgica, ruminando sombrios pensamentos quanto à dificuldade de viver em um universo hostil - com um céu assim tão baixo, até mesmo os canais têm vontade de se enforcar. Encontro um amigo e, à sua pergunta ritual "como você está?", posso invocar a cor do céu é o estado lamentável do mundo. Podemos muito bem imaginar que meu amigo me responde, e, se ele é convincente, que me faça, além disso, mudar de teoria, afirmando que isso é porque eu sem dúvida dormi mal e, assim, vejo tudo negro. Não somente duas etnoteorias foram invocadas - é o mundo que me deixa triste; o mundo assume a cor que nossas emoções lhe dão - mas elas se fizeram objeto de uma negociação. Meu amigo pôde pensar que eu deleguei muito rapidamente meu mal-estar ao mundo; ou a contradição entre meus sentimentos e os dele lhe pareceu menos suportável; ou ainda ele pôde simplesmente sentir compaixão e convocar uma teoria que, ele esperasse, agiria sobre meu humor (ou me ajudaria a relativizá-lo). As razões de minhas próprias opções etnoteóricas poderiam elas mesmas serem objetos de interpretações diversas, indo da tendência a atribuir aos eventos causalidades externas até a regras de pudor ou de cortesia que me impediriam de dizer explicitamente que eu não estava bem.

Os exemplos poderiam se multiplicar à vontade.

A idéia de que nós "utilizamos um potencial para a ambivalência" e que essa possibilidade tem sem dúvida favorecido a manutenção de definições contraditórias, certamente não responde à questão de saber de onde nos vem essas concepções de emoções. Responder a esta questão ultrapassaria amplamente o quadro de nossa reunião: seria necessário, por exemplo, retornar à filosofia de Platão para compreender como a dimensão de "periculosidade" que acompanha certas etnoteorias pôde vir à luz e analisar como o próprio pensamento cristão recuperou e prolongou esta idéia. Em contrapartida, a idéia de que as emoções são a vida, de que elas são a parte autêntica do indivíduo nos demandaria ir aos Românticos que nos influenciaram tão profundamente (especialmente a idéia de que as emoção são a expressão do eu verdadeiro: poderemos ler os trabalhos de Charles Taylor a esse respeito, particularmente As fontes do self (1989).

Ainda no quadro deste texto, o caminho que nos conduziria a refazer a história da formação de nossas emoções é muito longo. Eu proponho a vocês preferencialmente considerar as coisas em termos de questões atuais, que mostrem como certas concepções serão investidas pelas pessoas, utilizadas como estratégias relacionais, e então, mantidas vivas. Para fazê-lo, deixemos Lutz e vamos nos voltar à análise de um outro pensador da emoção, James Averill.

Analisemos com ele as questões desta versão da emoção que privilegiamos tanto e segundo a qual as emoções são aquilo "que nos transborda", "que nos acontece", o que explica que pensamos que elas sejam irracionais.

Podemos formular uma hipótese paralela à de Lutz (nós "utilizamos as concepções que nos reorganizam") e pensar que a experiência de transbordamento pode, como experiência, permitir pensar e negociar as relações consigo mesmo, com os outros e com o mundo. Nossa experiência mais comum não nos ensina 
quando dizemos "desculpe-me, estava encolerizado, eu não me controlava mais, eu não pensava o que eu estava dizendo"? Nossa cultura, além disso, criou expressões espantosas para exprimir essa irracionalidade, essa estranheza da paixão - "eu não era mais eu mesmo". Estas expressões testemunham inicialmente uma outra coisa: esta incontrolabilidade e esta passividade da paixão nos fascinam e não cessamos de traduzir esta fascinação. Podemos certamente reatar esta experiência da passividade e da irracionalidade à nossa concepção de responsabilidade, ligada à racionalidade e à integridade da pessoa, e esta fascinação ao fato de que nossa tradição atribui um valor importante à ação deliberada. Mas isso não explica grandes coisas, sobretudo isso não permite compreender como de certa maneira, "desviamos" este privilégio atribuído à racionalidade. Esta ligação entre a fascinação e o privilégio da racionalidade não é uma simples consequência, que traduziria o fato que "porque estamos em uma cultura que privilegia a racionalidade, todo aquilo que transborda esta última nos fascina como um problema": esta fascinação não é o sintoma de um problema (a tensão entre a razão e a paixão, a ameaça da paixão para a razão), mas traduz a maneira como nós cultivamos a relação a determinados problemas, ou mais precisamente, a maneira como utilizamos as dimensões do contraste emoção-razão para negociar e resolver estes problemas. É isto que eu chamo "desviar o privilégio atribuído à racionalidade".

Segundo o psicólogo construtivista James Averill, a experiência de passividade que condiciona nossas teorias da emoção seria de fato uma "ilusão" que temos ou que criamos a propósito daquilo que são nossas experiências emocionais. Mas, essa passividade da experiência emocional não é uma ilusão da qual seríamos vítimas passivas, ela deve ser lida, segundo Averill, como uma estratégia social, isto é como uma estratégia de negociação consigo mesmo e com os outros. A experiência de passividade, a experiência pela qual as emoções são "coisas que nos acontecem", que são "naturais" e independentes de nossa razão e de nossa vontade, esta experiência que, aliás, há muito tempo legitimou as concepções naturalistas, deve ser interpretada como uma maneira a partir da qual negociamos a relação com nossos atos. No caso da maior parte das emoções, ele explica, o indivíduo não pode ou não quer aceitar a responsabilidade de sua ação: a iniciação da resposta é portanto dissociada da consciência. E de lá que viria nossa reconstrução da experiência em termos de passividade, como se o que nos faz agir seja uma espécie de núcleo natural dissociado do resto da pessoa. Esta experiência de passividade, de transbordamento, de não controle seria, portanto, a maneira como negociamos nossos atos, conosco mesmos em um modo ilusório - poderíamos dizer em um modo de má-fé -, e com os outros em um modo de negação (não sou eu). Aquilo a que a emoção assim construída nos engaja, então, seria uma experiência da multiplicidade, em um modo de "ser um outro", o que nos permite em ultima instância afirmar um "não ser". É uma estratégia que nos permite agir sem assumir a responsabilidade de nossa ação, semelhante, diz Averill, às estratégias da histérica que mente a si mesma para se liberar de suas responsabilidades e de sua culpabilidade. 
Essa interpretação de Averill ilumina com uma luz completamente diferente uma particularidade de nossa cultura: o fato que a paixão, experimentada como evento ou como experiência de transbordamento, torne-se uma categoria jurídica, pois o jurídico considera como precisamente legitimo oferecer um tratamento diferente aos crimes ditos passionais. As experiências de síndrome Amok, ou dos "homens selvagens" das regiões polinésias seriam assim desta ordem e poderiam receber uma leitura similar. Com efeito, nesses casos, como no nosso, a maneira como cultivamos determinadas dimensões da emoção permitiria resolver os conflitos de demandas dentro de um sistema cultural. $\mathrm{O}$ indivíduo socializado resolve o conflito entre dois sistemas de normas, dissociando a iniciação do ato proibido da consciência e ficando "transbordado pela emoção".

Se consideramos que cultivamos essas estratégias, a cultura, nessa perspectiva, não se define mais somente como aquilo que oferece suporte às nossas emoções. Ela não nos oferece somente os esquemas para pensá-las ou para dizê-las; ela faz muito mais que traduzir uma experiência que seria culturalmente dependente: ela é uma poderosa indutora já que induz o transbordamento. Não somente cultivamos uma experiência da paixão que a define como "evento fora de controle", mas cultivamos os modos do transbordamento passional, induzindo-nos este transbordamento. Nossa experiência com o álcool poderia se mostrar similar: certamente sabemos que sob a influência do álcool não nos controlamos bem. Mas quantos dentre nós não bebemos justamente para perder este controle, para ter a coragem de dizer, de fazer ou de se zangar? É o álcool que induz este transbordamento, ou é a maneira culturalmente sancionada pela qual podemos pedir à bebida que nos transborde? Nesse caso, o álcool é muito menos a causa de seu transbordamento que seu vetor; nós o utilizamos como um recurso nos permitindo este "ser outro" que pode responder em nosso lugar. Utilizamos como recurso, sobretudo, o fato de que nós podemos cultivar uma versão indeterminada da experiência, isto é, uma versão de que somos livres para distribuir as determinações: a experiência emocional (ou sob influência) pode ser induzida e indutora; causa, vetor e produto. O que significa também que cultivamos o contraste entre a autenticidade da experiência e a possibilidade de construí-la como tal, em um modo que não é mais aquele da disjunção, em um modo que, paradoxalmente, desestabiliza esse contraste: essas experiências, mesmo induzidas, não nos parecem menos "verdadeiras". A autenticidade com a qual elas se dão a nós testemunha que cultivamos tão bem as respostas que elas nos habitam, que elas se tornam os modos privilegiados de relação com o mundo e conosco mesmos.

Partimos dos ifaluk para chegar, após um longo desvio, à maneira pela qual cultivamos o álcool e as possibilidades sociais que ele nos oferece: além do fato de que esta última experiência nos mostra que, com efeito, é bem possível viver os fenômenos simultaneamente como construídos e como "reais", o próprio caminho nos ensina o interesse deste tipo de empenho: ficamos um pouco estranhos a nós mesmos nos encontros com os outros. 


\section{Notas}

${ }^{1}$ Comunicação pessoal.

${ }^{2}$ Se Lutz tinha razão de pensar assim, isso não é sempre o caso. Os beduínos do Egito estudados por Lila Abu-Lughod (1990) se singularizam por um contraste impressionante: eles valorizam as emoções na poesia, mas jamais fazem referência a elas no discurso cotidiano.

${ }^{3}$ Lutz explica que a posição das mulheres teve que se modificar ao longo dos últimos 50 anos e, sobretudo, sob a influência consecutiva de colonizadores japoneses e de programas de ajuda americanos. Nas duas situações, os colonizadores e seus alter egos humanitários colocaram os homens em postos chaves, os enviaram para estudar no estrangeiro e então lhes deram a responsabilidade pelos programas de financiamento.

${ }^{4} \mathrm{O}$ que, paradoxalmente, designa ainda mais aquilo "de onde viemos", pois a própria reflexividade faz parte de nossa cultura, tanto quanto a confiança que nós lhe outorgamos para ficar mais perto da verdade. Os que nos coloca finalmente na posição do Barão de Munchaüsen, que, vendo seu cavalo atolado em um brejo, puxa sua crina, mantendo-se na sela, para dali sair.

${ }^{5}$ Apresento aqui apenas um dos aspectos da etnologia dos Ifaluks e da teoria de Lutz. Os artigos de Lutz aos quais me refiro serão então mais amplamente comentados: Lutz (1983, 1986, 1990).

${ }^{6} \mathrm{~A}$ introspecção existe, mas ela pode tomar duas formas, uma valorizada, a outra, não. A primeira é considerada como um instrumento, não como um fim, que permite, quando de conflitos interpessoais, "se dividir em sua cabeça" para avaliar sua posição dentro do conflito e sua própria ação. No segundo caso, os pensamentos excessivos, sem objetivo moral, a fazem aparecer como ruim, e ela pode conduzir à doença ou à perda de apetite. A introspecção é benéfica se ela se dirige, como instrumento, ao mundo social (LUTZ, 1992).

${ }^{7}$ Eu remeteria, para uma bela análise dessa faculdade de hesitar, ao trabalho de William James, (1958) Essays in Radical Empiricism. New-York: Longman Green (1. ed. 1912).

\section{REFERÊNCIAS}

ABU-LUGHOD, L. Shifting politics in bedouin love poetry. In: LUTZ, C.; ABU-LUGHOD, L. (Ed.). Language and the politics of emotions. Cambridge: Cambridge University, 1990. p. 24-45.

LUTZ, C. Parental goals, ethnopsychology and the development of emotional meanings. Ethos, [S.1.], v. 11, n. 4, p. 246-263, 1983.

LUTZ, C. The domain of emotions word on Ifaluk. In: HARRÉ, R. (Ed.). The social construction of emotions. Oxford: Basill Blackwell, 1986. p. 267-288.

LUTZ, C. Unnatural Emotions: everyday sentiments on a Micronesian atoll and their challenge to western theory. Chicago: University of Chicago, 1988.

LUTZ, C. Morality, domination and understandig of "justifiable anger" among the Ifaluk. In: SEMIN, G.; GERGEN, K. Everyday understanding. Londres: Sage, 1990. p. 204-226.

LUTZ, C. Culture and consciousness: a problem in the anthropology of knowledge. In: KESSEL, F. S.; COLE, P. M.; JOHNSON, D. L. (Ed.). Self and Consciousness. Hillsdale, NJ: Lawrence Erlbaum Associates, 1992. p. 64-87.

TAYLOR, C. Sources of the Self: the making of the modern identity. Cambridge, Mass: Harvard University Press, 1989. 
As ciências da emoção estão impregnadas de política? Catherine Lutz e a questão do gênero das emoções

Recebido em: setembro de 2010

Aceito em: dezembro de 2010 